\title{
ACUTE INVAGINATION OF THE INTESTINE IN SMALL CHILDREN.
}

\author{
BY
}

\author{
S. MONRAD, M.D.,
}

Chief Physician, Dronning Louise's Children's Hospital, Copenhagen.

In 1905, in the "Mitt. aus Grenzgebiet der Medic. u. Chir.," Hirschsprung recorded 107 cases of acute intestinal invagination observed by him in the course of 34 years (1871-1904). In referring to this paper, I shall only quote the treatment and its results. Seventy-three children were treated entirely by non-surgical means; 59 of these were cured and 14 died In 11 children an attempt at reduction was first tried and afterwards laparotomy was resorted to; of these three were cured and eight died. This gives a total of 84 cases, 62 of which were cured and 22 died, which corresponds to a mortality of $26 \cdot 2 \%$. Sixteen children were operated on in the first instance; three of these were cured and 13 died.

Seven children were not treated, either because they were moribund on adinission or because the invagination was only recognised at the autopsy.

During the 20 years (1906-1925) in which I have been in charge of the Dronning Louise's C'hildren's Hospital I have had altogether 115 cases of acute intestinal invagination, or $5 \cdot 75$ cases on an average per annum. I will now give an account of these cases.

\section{TABLE I.}

Age of the Children (115 cases).

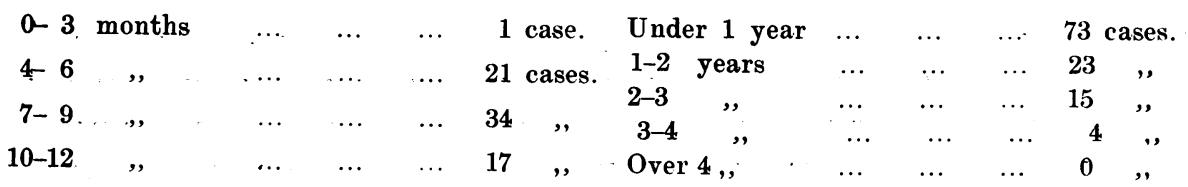

It will be seen from the above that I only had one case during the first three months of life, while in the third three months I encountered 34 cases or nearly one-third of the total number. Whether this has any connection with the fact that the seventh-ninth month is the period when weaning usually takes place I cannot say. As will be observed from the table, I had 73 children under 1 year of age, while none of them were over 4 .

\section{TABLE II.}

Sex of the Children (107 cases).

$\begin{array}{llllllllllll}\text { Boys } & \ldots & \ldots & \ldots & \ldots & \mathbf{7 2} \text { cases. } & \text { Girls } & \ldots & \ldots & \ldots & \ldots & 35 \text { cases. }\end{array}$

'The reason that only 107 children are recorded here, although I had 115 cases, is that five children got invagination twice and one child no less than four times, 
As the table shows there were twice as many boys as girls. This marked difference in sex, which is also found in most sets of statistics, has given rise to various ætiological theories (retention of the testis, phimosis, etc.) to which I do not believe any value whatever can be attributed. I shall, therefore, merely recall that such different diseases as congenital pyloric stenosis and infantile tetany exhibit exactly the same sex distinction.

Of the 107 children, 50, or about half, were the only children in the family, a phenomenon which is found in many other series of statistics and which cannot be explained.

Of the 73 infants under 1 year of age, 26 were entirely breast-fed and 40 received allaitement mixte, while only seven were bottle-fed. This fact is interesting because it shows that artificial feeding does not predispose to invagination.

Of the 107 children, no less than 74 were absolutely healthy at the time when the invagination occurred; 15 had antecedent diarrhœa and 11 were said to be inclined to be constipated. In seven of the children the information was doubtful.

It will thus be seen that acute invagination of the intestine in particular attacks healthy breast-fed children and those having allaitement mixte. Whether this depends upon breast-fed children having weaker antiperistalsis than bottle-fed ones I am unable to say. Further, it is observed that the disease has a special predilection for solitary children.

According to the available evidence, acute invagination of the intestine seems to be commoner in the Anglo-American countries and in Denmark than in many other lands, such as, for example. France, Germany, Norway and Sweden. Although it has been maintained that this difference in frequencv is due to the abuse of purgatives in the first-named countries, I can vouch for the fact that at any rate in the case of Denmark such a contention is quite without foundation. On going through the clinical histories of $\mathrm{mv}$ cases I have found that onlv a very few of the children received nurgatives immediately preceding the occurrence of the invagination.

In the nresent article, however, I shall not enter further into the different rtiolngical and pathogenetic theories which have seen the light of day, but I will nass on to discuss the different forms of intussusception which my material embraces.

Forms of Intussusception.

Onlv acute descending invaginations are being dealt with here. Chronic; invaginations in my experience are extremely rare in small children; and as regards ascending invaginations they are certainly not rare, but they practically all come on in agony and are therefore unimportant clinically.

There are many different forms of acute descending invaginations, but unfortunately the various authors do not regard them in the same light, in fact they even give different names to the same forms. This want of uniformity in the point of view and nomenclature unhappily makes it quite impossible to draw reliable conclusions from the different series of statistics. 
My own standpoint is as follows: I divide invaginations into two main groups-large intestine and small intestine invaginations. Each of these main groups are again divided into two sub-groups:-

I.-Large intestine invaginations are either purely colic, that is to say where a variable portion of the colon is invaginated in a lower part of the colon, or ileo-cœeal, i.e., where the head of the invagination is formed by the cœcum or ileo-cœcal valve. In the latter variety the vermiform appendix is thus situated in the intussuscipiens.

II.-Small intestine invaginations are either purely iliac, that is to say where a piece of small intestine is invaginated in a piece of small intestine below it, or ileo-colic by which is understood a small intestine invagination, situated low down, which goes through the ileo-cœcal valve and is found in the ascending colon or sometimes goes further down into the colon. In the latter form, therefore, the cœcum and appendix are external to the invagination in contrast to the ileo-cœeal invagination.

Besides these principal forms there are mixed forms and double forms, but as these are quite exceptional in my material I will not deal further with them.

My material contains the following forms:-

TABLE III.

\begin{tabular}{|c|c|c|c|c|c|c|c|}
\hline Large intestine & invaginations & ... & $\ldots$ & Total & 187 & cases & $(75.7 \%)$ \\
\hline Ileo-coecal & 0 & $\ldots$ & $\ldots$ & $\ldots$ & 66 & , & $(57 \cdot 4 \%)$ \\
\hline Colic & & $\ldots$ & $\ldots$ & $\ldots$ & 21 & ,, & $(18 \cdot 3 \%)$. \\
\hline Small intestine & invaginations & $\cdots$ & $\ldots$ & Total & 125 & cases & $(21 \cdot 7 \%)$. \\
\hline Ileo-colic & ," & $\ldots$ & $\ldots$ & $\ldots$ & 19 & ," & $(16.5 \%)$. \\
\hline Iliac & , & $\ldots$ & $\ldots$ & $\ldots$ & 6 & , & $(5 \cdot 2 \%)$. \\
\hline
\end{tabular}

In addition to these there were three mixed forms, namely, two iliacileocœcal invaginations and one iliac-ileocolic.

It will thus be observed that three-quarters of all my intussusceptions are of the large intestine and only one-quarter involve the small intestine. Further, over a half of all the cases are ileo cœcal invaginations, a fact which, moreover, is found in almost all statistics.

It is of great interest to see how the various forms differ with respect to the age of the children. Out of 87 large intestine invaginations no less than 59 occurred in infants under 1 year old, and only 28 in children over 1 year old. But out of the 25 small intestine invaginations only 11 occurred in children under 1 year old, while there were 14 in children over 1 year old.

Small intestine invaginations are, therefore, relatively rare in the firsi year of life and increase in frequency with age, but large intestine invaginations are particularly common in the first year, probably on account of the anatomical conditions, for-as is known-infants under 1 year have a high ascending mesocolon and a long, mobile sigmoid flexure. 


\section{Clinicali Ffatures.}

Acute intestinal invagination has four cardinal symptoms: (1) periodic attacks of colic; (2) vomiting; (3) passage of blood and slime per anum; and (4) presence of a tumour in the abdomen.

(1) Pain is the most constant and usually also the first symptom, as it is due to tension and dragging on the mesentery and, therefore, it undoubtedly sets in immediately the invagination occurs. It often starts very suddenly and takes the form of peristaltic attacks of colic which may be so violent that the child not only suffers intensely, but sometimes even collapses. On the other hand it is remarkable that in the pain-free intervals the children often do not convey the impression of being seriously ill at all. They lie quietly and have a moist, clean tongue, normal temperature, good pulse and an abdomen which is not distended and in its appearance in no way betrays what is happening in its interior. But it should be noted that the children are almost always remarkably pale and have a characteristic apathetic facial expression which is almost typical of patients with invagination. No wonder therefore that not only the mother, but also the doctor, who is not familiar with the clinical aspect of intussusception, may be puzzled by the peacefulness and apparent comfort displayed by the child in the intervals between the attacks of pain.

(2) The second cardinal symptom is vomiting which usually appears shortly after the pain has set in, but sometimes not until five-ten hours afterwards. In rare cases vomiting may be the first symptom and only very exceptionally is it entirely absent. The vomit at first consists of food, and later contains a lot of bile, but is never fæculent when the case is not an old one. I have nnet with two cases of vomit containing blood, which is stated to be very rare, in both instances in children with ileo-colic invaginations.

Like the pain, vomiting is an extremely constant symptom. Both of them are most severe and more prolonged in small intestine invaginations than in large intestine invaginations, and on the whole it is the rule that small intestine invaginations produce more rapidly appearing fever and greater general disturbance than happens in the case of large intestine invaginations.

(3) The third cardinal symptom is the passage of blood and slime pei anum. As a rule a natural motion is passed simultaneously with, or shortly after, the pain and vomiting have started, but then intestinal obstruction occurs, for neither fæces nor flatus is passed, but only bleor and slime, either spontaneously, or on examination, or with an enema. Usually there is only a small quantity of blood and slime, but sometimes there may be much hæmorrhage and this indicates that probably it is a colic invagination. It is characteristic of the blood and slime that it is not mixed with fæces and possesses no fæcal smell, but has a peculiar insipid odour which is 
absolutely typical, in fact almost pathognomonic of invaginations. It is important to remember this because there is another disease in which blood and slime are passed per anum and which is therefore not uncommonly confused with intussusception, namely follicular entero-colitis. But in this disease the blood and slime are mixed with the motions and have a pronounced fæcal smell. Moreover there are, as a rule, both fever and intoxication right from the very onset of the illness, symptoms which never occur in connection with recent intussusception.

The passing of typical blood and slime is pathognomonic of intussusception, but is not by any means constantly found. In my cases the facts were as follows. In all the 21 colic invaginations there was passage of blood and slime. In the 66 ileo-cecal invaginations this symptom was present in 61 cases, but was absent in five. In the 19 ileo-colic invaginations the passage of blood was absent in only one case, but in five of the six iliac invaginations it did not occur.

From this it will be observed that the presence or absence of this symptom may be a guide in deciding which form of invagination we have to deal with in any given case.

Of greater importance in topical diagnosis however is perhaps the stage of the disease at which the passage of blood starts. On this point my material indicates the following:-

TABLE IV.

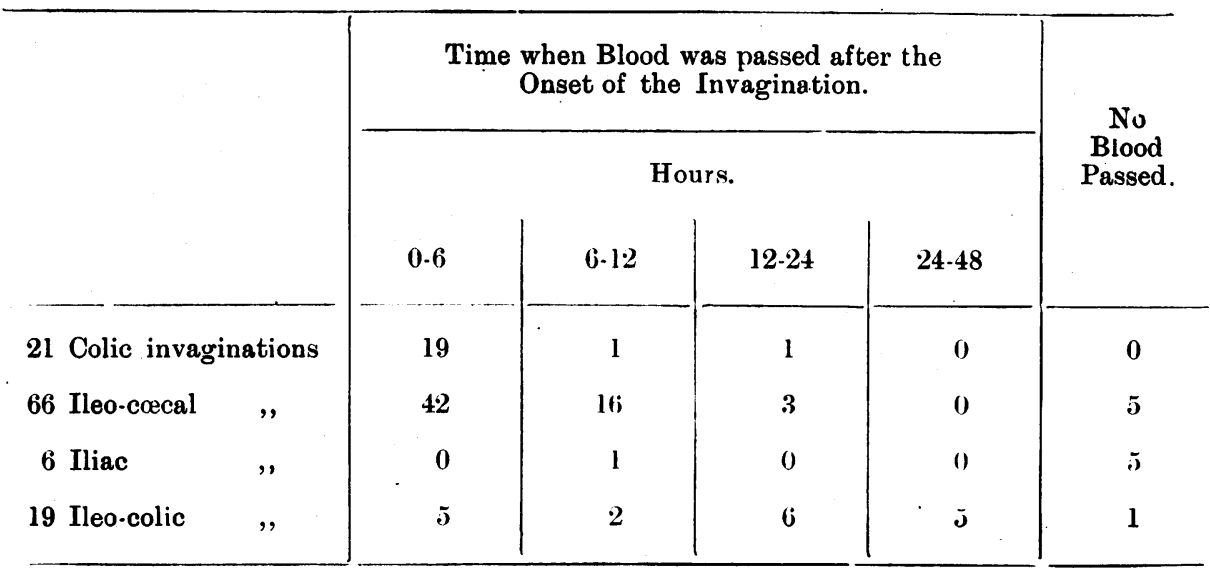

From this it will be seen that in large intestine invaginations the passage of blood occurred immediately or during the first 12 hours of the illness in about $90 \%$ of the cases, while in no case did it take place later than the first 24 hours (apart from the five cases where none at all was passed). It was quite different with the ileo-colic invagination, where in over half of the cases blood did not appear until 12-48 hours after the invagination had started. In the iliac invagination no blood was seen as a rule. 
(4) The fourth cardinal symptom is the invagination tumour in the abdomen. The demonstration of this is often difficult without narcosis, even in cases where a long tumour is present, and one must, therefore, never refrain from diagnosing intussusception because a tumour cannot be detected without an anæsthetic. It is almost always possible to palpate an invagination tumour under an anæsthetic, and amongst my cases I have only six in which I could not detect any tumour. One case was an ileo-colic invagination of 12 hours' standing in a child of 8 months, where the lesion was only recognised at the autopsy. The other five cases were probably colic invaginations; there were attacks of colic, vomiting, the passage of typical blood and slime, and the invaginations were easily reduced by means of injections of water.

I was able to palpate the invagination tumour in 109 cases, and I will now give a brief account of the situation, size and other relations of these tumours in the different forms of invagination.

In the ileo-cocal invagination the commonest finding was a bananashaped tumour lying to the right of the umbilicus and stretching up towards the right costal margin. I have found a tumour of a size and shape like that shown in Fig. 1 in over half of my cases of ileo-cœeal invaginations. In some cases very long tumours are found which extend right over into the left side of the abdomen (Fig. 2). Sometimes parts of the swelling may

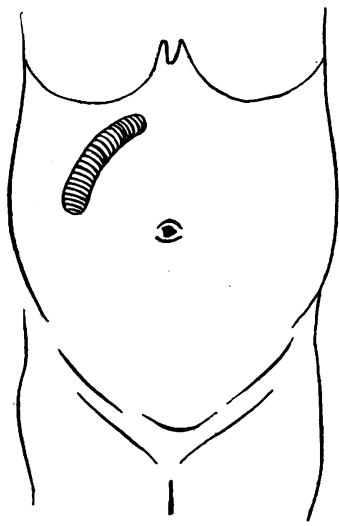

Fig. 1.-Inv. Ileo-cocal, 29 hours ( 97 montl:s)

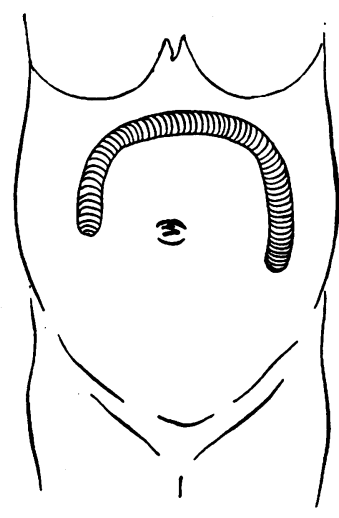

Fig. 2.-Inv. Ileo-coeal, 9 hours ( 93 months)

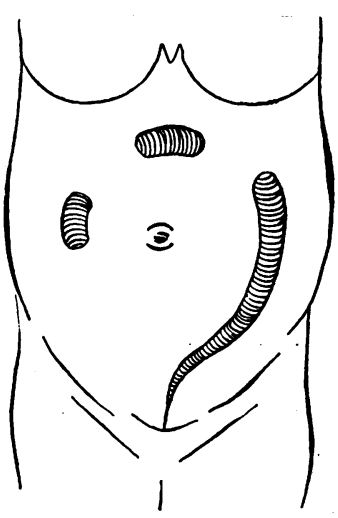

Eig. 3.-Inv. Ileo-cocal, 20 hours ( $\$ 7$ months)

be hidden, so that one at first thinks there are several separate tumours (Fig. 3), but as soon as one begins to reduce it, it is soon discovered that there is only one tumour. In only eight out of 66 ileo-cecal invaginations was the tumour palpable in the rectum. It may be added that the length of the tumour is independent of the duration of the illness; the relatively small tumour seen in Fig 1, for instance, was due to an invagination which had lasted for 29 hours, while the long one in Fig. 2 had only existed for nine hours. 
In colic invaginations the tumour ahmost always lies to the left of the umbilicus, corresponding with the descending colon, and has an almost vertical course (Fig. 4). Sometimes, however, the tumour is only felt

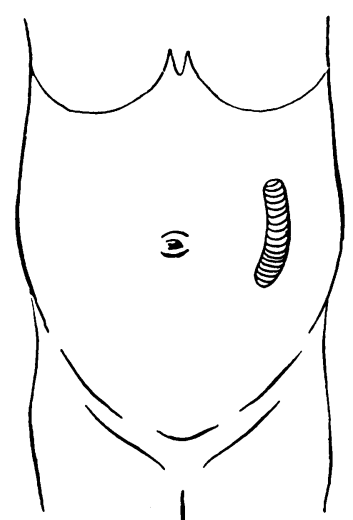

Fig. 4.-Inv. Colic, 32 hour: (o 5 months)

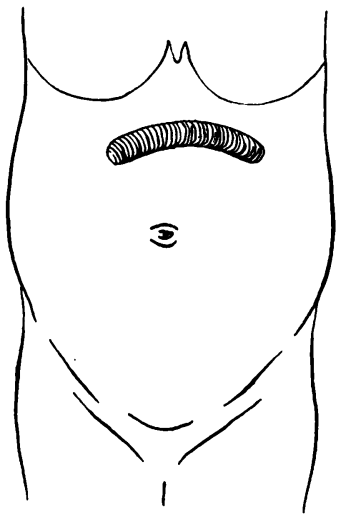

Fig. 5-Inv. Colic, 3 hours (o 9 months)

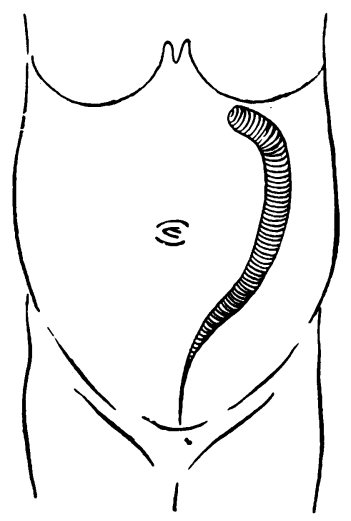

Fig. 6. - Inv. Colic, 2 hours(o 1 year)

in the transverse colon (Fig. 5). That the tumour is easily palpable in the rectum (Fig. 6) is natural and this was also the case of seven of my 16 patients with colic invagination. It is also true of the colic invagination tumours that their length bears no relation to the duration of the disease; the tumour in Fig. 4 for instance was due to an invagination which had lasted for 32 hours, while that in Fig. 6 had lasted only two hours.

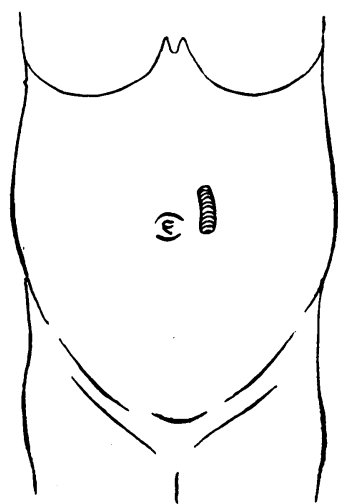

Fig. 7.-Inv. Iliac, 12 hours (o 1 year)

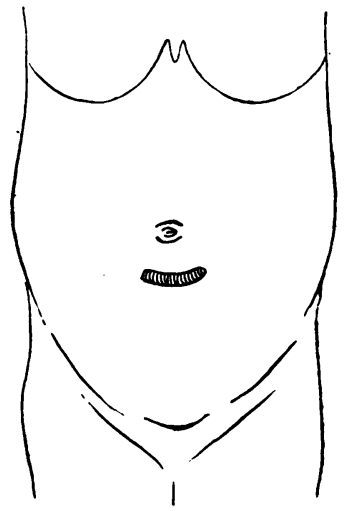

Fig. 8.-Inv. Iliac, 6 hours ( 86 months)

Iliac invaginations are always small, short, thin and very mobile tumours lying in the neighbourhood of the umbilicus (Figs. 7 and 8) and they can readily be moved forward under the skin and roundabout in the abdomen. 
In over half of my ileo-colic invaginations I found a tumour of the size and in the situation shown in Fig. 9, thus one which is quite like that found in ileo-cœcal invaginations, but which is seldom as long as the latter. I have only one case in which the tumour was palpable in the rectum (Fig. 10);

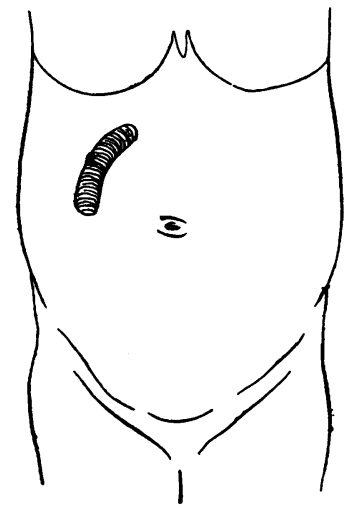

Fig. 9. - Inv. Ileo-colic, 9 hours ( 85 months)

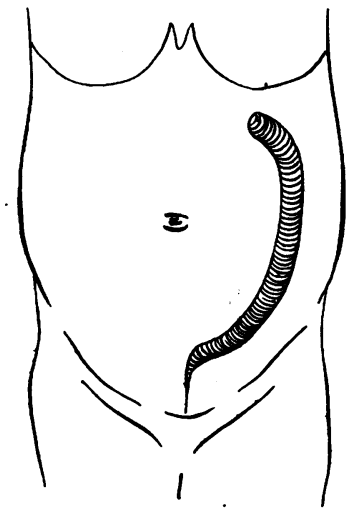

Fig. 10. - Inv. Ileo-colic, 12 hours ( $\$ 6$ months)

this tumour was also only felt in the left side of the abdomen. I have only observed such a left-sided tumour in one other case of ileo-colic invagination, but the post-mortem examination showed that the coecum was situated on the left side of the abdomen. Lastly, in three cases I found the tumour involving chiefly the transverse colon.

\section{Diagnosis.}

I have dealt fully with the four cardinal symptoms of these invaginations because it is of the greatest importance that they should be so impressed on the doctor's mind that he never overlooks an invagination or mistakes it for something else. When all the four symptoms are present no doubt ought to be possible; nor should there be doubt in a case where typicai blood and slime are passed per anum in conjunction with an attack of colic and vomiting. The mistake that may sometimes be made is that the symptom-complex may be interpreted as the manifestation of follicular enteritis. In one of my patients the passage of blood was so great and such a dominating feature that the child was admitted by the doctor with the diagnosis: "hemorrhagia per anum, periculum in mora." On the other hand, it should be remembered that there are invaginations where typical blood and slime are not passed for 24 hours or. more after the illness has begun, and lastly, as I mentioned above, there are invaginations where practically no bleeding occurs. That one must not allow oneself to be misled by the apparent well-being and calm appearance which the majority of children with intussusception display in the free intervals between the attacks of colic, cannot be too strongly emphasised. 


\section{ACUTE INVAGINATION OF INTESTINE IN SMALL CHILDREN 331}

Topical Diagnosis. When the diagnosis of invagination has been made the next question is whether one can decide from the clinical symptoms and physical signs what form of invagination one has to deal with. I am quite aware that such a topical diagnosis is difficult and needs some experience, but as it is of the greatest importance both for the prognosis of the disease and the treatment one ought always to try to get as near to it as possible. I will, therefore, briefly pass in review the factors which are most helpful to me in the differential diagnosis between the four chief forms.

In the colic invagination, the tumour usually lies in the left side of the abdomen, corresponding to the descending colon and has an almost vertical course; it can often be felt in the rectum. More rarely it is situated above the umbilicus, corresponding to the transverse colon. It is characteristic of all colic invaginations that they always cause hæmorrhage and that the passing of blood takes place immediately or, at all events, within six hours of the occurrence of the invagination.

Iliac invaginations are always small, short, thin and very mobile tumours. As a rule no blood is passed, but fever and malaise set in more quickly.

If these forms are therefore, as a rule, easy to diagnose, the difficulties are so much the greater when it comes to making a differential diagnosis between ileo-cœcal and ileo-colic invaginations. Definite conclusions can only rarely be drawn from the situation, shape and size of the tumour, as those found in these two forms are often quite identical. But I am of opinion that if a rounded or oblong swelling which is difficult to define, can be felt, deep down in the ileo-cœcal region one should always think of ileocolic invagination. The so-called Dance's sign (an emptiness in the right iliac fossa which is said to be characteristic of ileo-coecal invagination) has never been of help to me, but has, on the contrary, sometimes led me astray. The points which I make use of in the differential diagnosis, besides what was said above about the tumour itself, are: (1) in children under one year the ileo-cœeal is by far the commonest form, while the ileo-colic is more frequent in older children; (2) in the ileo-cœeal form bleeding usually occurs immediately or within 12 hours of the occurrence of the invagination, whereas in the ileo-colic form bleeding, as a rule takes place later, 12, 24, or 48 hours afterwards; (3) the ileo-colic form commonly ciuses more severe attacks of colic and more violent vomiting than the ileo-cecal; and (4) in the ileo-colic form fever usually sets in more quickly and there is more malaise than in the ileo-cocal variety.

With the aid of this information I believe that the correct differential diagnosis can often be inade, but I will not disguise the fact that I have unfortunately sometimes failed.

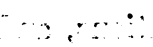




\section{'Treatment'.}

I will now pass on to discuss the treatment. I will start by pointing out that the treatment of acute invagination of the intestine ought to be carried out only at a hospital.

When the practitioner has diagnosed intussusception, in fact, even if he only has a suspicion of it, he should immediately send the child to a hospital and not waste valuable time with narcotics and non-surgical attempts at reducing it at home. On this point I must very decidedly disagree with Hirschsprung and Wichmann, both of whom advocate the feasibility of treatment at home. Throughout Denmark admission to hospital is so easy and expeditious that there is no excuse for beginning to treat acute intestinal invagination in the patient's home.

But the question now is: What treatment shall the hospital dcctor choose?

That reduction of the invagination by primary laparotomy is and must be the ideal treatment, all are agreed. But the fact is that this method of treatment in children in the first, and even in the second year of life, has been associated with a surprisingly high mortality almost everywhere throughout the world. No wonder, therefore, that attempts have been made to save a healthy child's life by non-surgical reduction of the invagination, and Hirschsprung, as is known, has gained imperishable credit for advocating the bloodless treatment. Encouraged by the results which I had the opportunity of seeing when I was Assistant Physician under Hirschsprung, I have naturally followed up this method, with what result will now be seen.

When the bloodless method of treatment is mentioned in the literature, water injections into the intestine are almost always spoken of (Wassereinspritzungen, irrigations, hydrostatic pressure, etc.), and there seems, therefore, to be a general impression that the bloodless reduction of an invagination is principally effected by injecting water into the intestine. Both Hirschsprung and Wichmann themselves are responsible for this view becoming so universal, for although they both employed and discussed the massage treatment, they conclude by laying the greatest stress on water injections.

That I, as a pupil of Hirschsprung, also at first attributed most importance to the action of water pressure goes without saying. But although this treatment led in many cases to the desired result I soon became aware that the method had its great drawbacks, and what specially worried me was that when water had been introduced into the intestine and the abdomen distended, the tumour could no longer be felt, and, moreover, it was naturally easily displaced by the water injection. One was thus prevented from following whether it became larger or smaller from the manipulations, and the massage was really applied haphazard. The method, 
moreover, was inapplicable to small intestine invaginations, for water pressure treatment in these forms is ineffective. $I$, therefore, soon abandoned this procedure and placed more reliance on regular taxis.

The method I use is as follows. After the bladder and perhaps the stomach are emptied, the child is put deeply under an aniesthetic, for which purpose I always use chloroform, because I do not get the abdominal muscles so relaxed with ether narcosis as they necessarily have to be in order that regular taxis can be performed. When the child is unconscious I palpate the whole of the invagination swelling as accurately as possible and try to reduce it by going to work in the following manner.

If it is a large intestine invagination, an ileo-cecal or a colic one, I first grasp the neck of the invagination with both hands and compress it for one or two minutes to diminish the œdema and blood extravasation. I then steady the neck with the left hand, take hold of the apex with the right hand and try to reduce the invagination by pulling the intussusception back through the intestine. Sometimes it can easily be reduced, at others it may be very difficult and needs considerable strength, but in no case do I persist in these taxis manipulations beyond 10 or, at most, 15 minutes.

If it is an iliac invagination, in which one cannot at first tell where the neck and head are, I grasp the two ends of the tumour and cautiously pull from each side alternatively, until I find that the invagination is reduced. In this form of invagination I never try taxis for more than five minutes. If by then the invagination has not shown the least sign of yielding there is a great probability that it is complicated by a polypus or a Meckel's diverticulum, and then only harm will be done by continuing the taxis.

After the taxis is finished, whether it is considered to have succeeded or not, I inject water into the intestine, using, as Hirschsprung does, an enema syringe and Oser's sound which are introduced as high up as possible. While an assistant compresses the nates around the sound, I pump in water with one hand and place the other one flat on the abdomen so as to judge the degree of distension. When this has become so great that water begins to ooze out of the anus at the side of the sound, I stop pumping and let the water run slowly out.again.

Previously, I always gave two, three or four such water injections in succession; now I am usually satisfied with a single one or at most two, because as I have said, I place more reliance on dry taxis than on water pressure for reducing the invagination. But it is chiefly for other reasons that I always finish with a water injection. In the first place, one often obtains pronf in this way that the invagination is reduced, namely, when on letting out the water fæcal particles come away with it towards the end. In the second place, by washing ont with water, toxic substances which have accumulated above the site of the invagination are often got rid of, and thus the danger of intoxication is lessened. And lastly, by leaving some of the water behind in the intestine to be absorbed, the turgor of the tissues is increased and so the child's resistance is enhanced. 
When the entire procedure (dry taxis and water injection) is finished, which usually takes 20 to 30 minutes, the child is put to bed with a binder round its abdomen; it is provided with hot bottles and, if necessary, recelves camphor injections and subcutaneous injections of salt solution. Until the first motion is passed the child only receives boiled water to drink and in small quantities at a time. No medicine is given by the mouth and, in particular, I never give opium or purgatives.

Unlike Hirschsprung I never make more than one bloodless attempt at reducing the intussusception; if this fails $I$ resort to laparotomy.

I will add that $I$ have never seen rupture of the intestine occur as a result of this treatment. It is possible that in difficult cases of reduction where enormous force must often be used, rupture of the serous covering of the gut may take place, but it also happens now and again in operative reduction, and there are not many surgeons who attribute so much importance to these ruptures that they would lengthen the operation by suturing them. However this may be, I have, at any rate up to the present, never had a case of rupture of the intestine or peritonitis following bloodless taxis.

The bloodless treatment here described necessarily demands some practice, but it is perfectly straightforward to carry out and the majority of house physicians whom I have had in the course of years have rapidly: acquired the technique and have performed many reductions of intussusceptions.

I now come to the question which is as important as it is difficult: Is the invagination reduced or not?

It is perfectly clear to me that we are here up against the "Achilles heel" of the bloodless treatment. This is the point which needs most experience and where a false conclusion is always fatal to the child's. life.

When one has done taxis one will nearly always be able to feel a tumour of larger or smailer size at the place which corresponds with the neck of the invagination. To decide whether this swelling is the last unreduced part of the intussusceptum or merely the thickened wall of the intestine, needs a good deal of practice and experience. Partieularly in the ileo-cecal invagination, the cœcum, ileo-cnecal valve and mesenteric glands can be the seat of so much œdema and extravasation of blood after reduction of the invagination, that the whole region feels like a harl tumour the size of a walnut, which may well simulate the last remnant of the invagination. I admit that, especially in the early days, I frequently felt. very much in doubt about the interpretation of such a tumour, but of late I think I can say that my judgment is usually right.

The criterion of whether the invagination is reduced or not, is, of course, whether the mations are passed. This is also the reason, as stated above, that $I$ always give a water injection after taxis and make a careful inspection for particles of fæces in the water that comes away. 
Altogether I have reduced 75 intussusceptions by bloodless taxis, and in these the times when the first motion was passed after reduction were as follows :-

TABLE V.

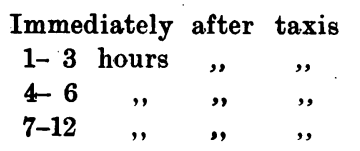

$\begin{array}{lccccccccc}\ldots & 33 & \text { cases. } & 16 & \text { hours } & \text { after } & \text { taxis } & \ldots & \ldots & 1 \text { case. } \\ \ldots & 12 & , & 22 & , & , & , & \ldots & \ldots & 2 \text { cases. } \\ \ldots & 14 & , & 30 & , & , & , & \ldots & \ldots & 1 \text { case. } \\ \ldots & 11 & , & 34 & , & , & , & \ldots & \ldots & 1 \quad,\end{array}$

As will be seen a motion was passed immediately in nearly half the cases, but often it was necessary to wait many hours. It is easy to understand that this period of waiting is often a very anxious and unpleasant one, but the trained observer will almost always be able to decide whether the invagination is reduced or not. The chief points to look for are whether the periodic attacks of colic return, whether the facial expression of the child again assumes the type which is characteristic of patients with intussusception and whether the passing of typical bloorl and slime per anum occurs afresh. But one must not be misled by the fact that very severe intoxication symptoms such as vomiting, high temperature, eclampsia, etc.. can also occur after taxis has been performed, for this is not uncommon. Intoxication after a bloodless reduction of an invagination may even be so great that death ensues. Thus three died of the 75 children in whom I succeeded in performing a bloodless reduction. First, a girl of 7 months who had a colic invagination which had lasted for 29 hours, with a tumsur whose size and position was about the same as that shown in Fig. 6. Reduction was simple, but she died 30 hours later with hyperpyrexia, and at the autopsy exhibited nothing beyond some ecchymoses in the sigmoid flexure, especially no invagination anywhere, no rupture of the intestine and no peritonitis. The second case was a girl 3 months old, with an ileo-cœcal invagination which had lasted nine hours (Fig. 2). In this patient also the invagination was easily reduced by the bloodless method, but she died three days later in a state of eclampsia. The third case was a boy, 5 months old, who had an invagination of nine hours' standing (Fig. 9). I thought I had to deal with an ileo-cœeal invagination and therefore performed bloodless taxis which succeeded, but he died after 24 hours with hyperpyrexia and eclampsia. No invagination, no rupture of the intestine and no sign of peritonitis were found at the autopsy, but it was seen that the invagination had not been an ileo-cœeal but an ileo-colic one, because the appendix and the mesentery were quite normal, and had, therefore, not been inside the invagination (preparation preserved). This last case is particularly interesting because it shows that it is really possible to reduce an ileo-colic invagination by the bloodless method. I shall not, however, allow this case to tempt me. Luck was here greater than intelligence, and I still firmly believe that if one has a suspicion that the invagination is an ilen-colic one. bloodless taxis must never be performed. 


\section{Results of Treatment.}

In conclusion, I will give an account of the results of the treatment of my cases.

As mentioned in the beginning, I have had experience of a total of 115 cases; five of them, however, did not get any treatment because two were unrecognised and only discovered at the autopsy, and three were admitted moribund and died a few hours afterwards. I have, therefore, 110 treated cases.

Of these, 16 were operated on primarily, with the result that five were cured and 11 died. It goes without saying that this high mortality $(68.8 \%)$ tells us nothing with respect to the prognosis of a primary operation, for it was only old and complicated cases that received surgical treatment primarily.

I have thus 94 cases which werc subiected to bloodless treatment. Of these, 84 received only this kind of treatment, while ten had a subsequent laparotomy performed after taxis had failed. The results are:-

TABLE VI.

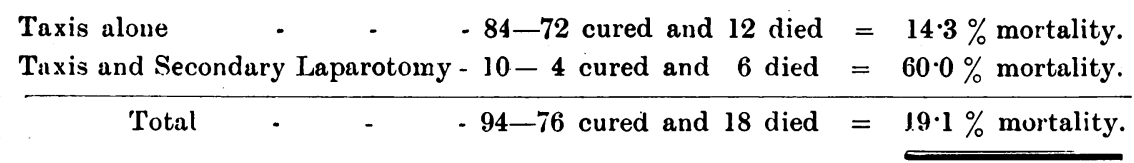

With regard to the secondary laparotomy, it has been asserted by many that this should always be done immediately and under the same narcosis as the taxis so as not to expose the child to repeated narcosis. It is possible that this view is correct in theory but it is impracticable, because it is often necessary to wait some hours before it can be decided whether taxis has been successful or not. Judging from my. cases it does not appear that the prognosis of secondary laparotomy is worse when some time elapses between the taxis and the operation. Thus the four children who were cured by secondary laparotomy were operated on from 14 to 20 hours after taxis had failed, whereas in the six who died the operation took place only a few hours after.

Of my 84 non-surgically treated cases, 12 died, as stated. Of these, three children died from intoxication in spite of taxis being performed, while the remainder (nine cases) died without a secondary operation being undertaken, either because they were in such a bad condition that I dared not risk a laparotomy or because I erroneously believed that the invagination had been reduced.

The effect of the bloodless treatment in the different forms of invagination is seen in Table VII. 
TABLE VII.

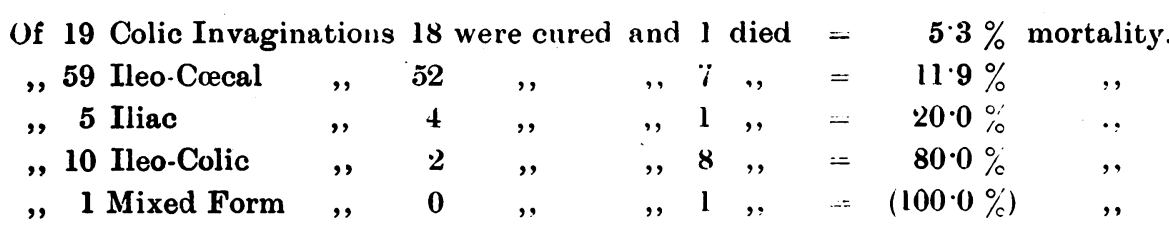

As will be seen from these records the bloodless treatment gives excellent results in the case of large intestine invaginations. I had altogether 78 large intestine invaginations and no less than 70 of these were cured, a death-rate of $10.25 \%$, a mortality which is not only far smaller than that of the majority of surgical statistics, but can also compare with the very best resultsshown by primary laparotomy. In Iliac invagination, which always shows a serious prognosis, the bloodless method has also given very satisfactory results, for it was carried out with success in four out of five cases. Besides the rare mixed forms, the worst form is the ileo colic invagination, for I had ten cases, eight of which died, or a mortality of $80 \%$. In all these cases I tried the bloodless treatment, because I wrongly supposed I was dealing with an ileo-cœcal invagination. One's efforts must, therefore, be directed towards perfecting the differential diagnosis between the ileo-colic and ileo-coecal forms, a task which is by no means easy but which is of the greatest importance because, as I have mentioned above, the bloodless treatment must never be attempted in cases of ileo-colic invagination. That one must likewise never try this treatment if one has a suspicion that the case is a mixed form of invagination, goes without saying.

The forms of invagination in which it is permissible to try the bloodless treatment are therefore the colic, the ileo-ceecal and the iliac. But this must not be interpreted as meaning that the bloodless treatment should be tried always and in all cases in these three forms of invagination, for that must not be done. The child's age and the length of time the invagination has lasted must also be taken into account. $\Lambda$ child over two years of age must, as a rule, never be treated by the bloodless method, but must immediately have laparotomy performed on it. With regard to the duration of the invagination, it depends on what form it is. Experience has gradually taught me to abide by the following rules.

In the colic form taxis may be tried provided that the invagination is not more than 36 hours old; in the ileo-cœeal form, when it is not more than 24 hours old; and in the iliac form when it is not more than 12 hours old. 
On this point my cases show the following:-

\section{TABLE VIII.}

18 Colic Invaginations under 36 hours with 1 death.

$\begin{array}{lllllll}52 \text { Ileo-Coecal } & . & , & 24 & , & ,, & 5 \text { deaths. } \\ 4 \text { Iliac } & ,, & ., & 12 & \text {, } & , & \text { 1 death. }\end{array}$

'These figures show a total of 74 cases of which only seven were fatal, that is to to say, a mortality of $9 \cdot 5 \%$.

These are the results of my 20 years experience of the bloodless treatment of acute intestinal invaginations in infants. And if they are compared with the results of a primary operation I cannot but think that; the bloodless treatment carried out in the right way and in accordance with the proper indications also has its legitimate sphere of usefulness. 